\title{
Zu Band IV, S. 302 f. d. Zeitschr.
}

Von Erwin Preuschen, cand. theol.

In Bd. IV, 302 f. d. Z. findet sich die Notiz, dafs E. F. C. Rosenmüller 1834 in der Vorrede zur Tauchnitzschen Stereotypausgabe des hebräischen A. T. zum erstenmale die Vermutung ausgesprochen habe, es möchten alle noch erhaltenen Handschriften des hebräischen Textes des A. T. auf eine Rezension zurückgehen und aus einer Quelle geflossen sein. Thatsächlich ist die Bemerkung schon älter, wenn auch Rosenmüller der erste gewesen zu sein scheint, welcher sie gemacht hat. Sie findet sich nämlich bereits in dem 1797 erschienenen 1. Bande des Handbuches der Literatur der Biblischen Kritik und Exegese, und zwar gelegentlich einer Besprechung der von Kennicott herausgegebenen Variantensammlung. Die betreffeñde Stelle (S. 247) lautet : „Dieser ganze, mit so vielem Aufwand von Zeit und Kosten zusammengeführte Variantenwust giebt übrigens das einfache Resultat : dafs alle noch vorhandene Codices im Verhältnis zu den Originalen sehr jung sind, ... dafs sie sehr reich an Schreibfehlern aber äufserst arm an wichtigen und brauchbaren Lesarten sind, dafs sie sämmtlich im Ganzen eine Rezension darstellen, aus einer Quelle geflossen sind, und dafs folglich aus ihnen für die etwa verdorbenen Stellen des hebräischen Textes wenig oder gar keine Hülfe zu erwarten ist." Rosenmüller hat dann seine Erkenntnis 1834 noch einmal ausgesprochen und ist abermals damit unbeachtet geblieben. Es zeigt dies Beispiel wieder einmal recht deutlich, wie schwer es oft hält, dafs sich richtige Erkenntnisse durchsetzen. (Vgl. übrigens auch D iestel, Geschichte des A. T. in der christl. Kirche 1869, S. 594.) 